Utah State University

DigitalCommons@USU

$5-1982$

\title{
Effects of Intermittent Reinforcement Upon Fixed-Ratio Discrimination
}

Tore Lydersen

Utah State University

Follow this and additional works at: https://digitalcommons.usu.edu/etd

Part of the Psychology Commons

\section{Recommended Citation}

Lydersen, Tore, "Effects of Intermittent Reinforcement Upon Fixed-Ratio Discrimination" (1982). All

Graduate Theses and Dissertations. 5927.

https://digitalcommons.usu.edu/etd/5927

This Dissertation is brought to you for free and open access by the Graduate Studies at DigitalCommons@USU. It has been accepted for inclusion in All Graduate Theses and Dissertations by an authorized administrator of DigitalCommons@USU. For more information, please contact digitalcommons@usu.edu.

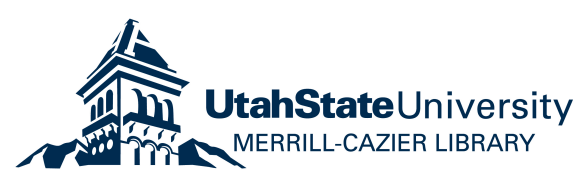


EFFECTS OF INTERMITTENT REINFORCEMENT UPON

FIXED-RATIO DISCRIMINATION

by

Tore Lydersen

A dissertation submitted in partial fulfullment of the requirements for the degree

of

DOCTOR OF PHILOSOPHY

in

Psychology

Approved:

UTAH STATE UNIVERSITY

Logan, Utah 


\section{ACKNOWLEDGMENTS}

I would like to extend my appreciation to the members of my committee and especially to Dr. Carl D. Cheney, under whose direction this research was conducted. I also would like to specifically thank Drs. E. K. Crossman and J. Grayson Osbome for many informative discussions that influenced the present research.

Without the encouragement of several very special people, this work would not have been possible. To my wife, Banbara, and my parents, go my deepest gratitude. 
TABLE OF CONTENTS

Page

ACKNOWIEDGMENTS

LIST OF TABLES

V

LIST OF FIGURES

vi

ABSTRACT $. \quad . \quad . \quad . \quad . \quad . \quad . \quad . \quad . \quad$. $\quad . \quad$ vii

INTRODUCTION

Background of Problem and Definition of Terms . 1

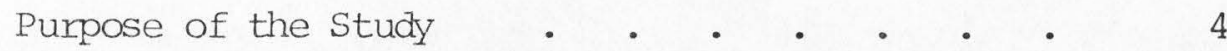

Research Design . . . . . . . . . . 44

Limitations and/or Delimitations of the Study . 5

REVIEW OF THE LITERATURE • • • • • • • • 6

Conditional Discrimination . . . . . . 6

Fixed-interval and variable-interval schedules 6

Fixed-ratio and variable ratio schedules . 11

Simultaneous Discrimination . . . . . . 18

Sumary • • • • • • • • • • • • • 26

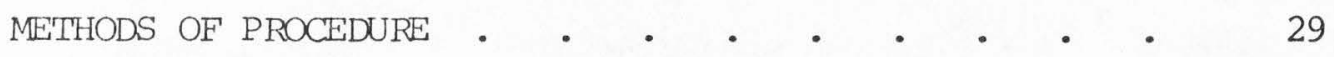

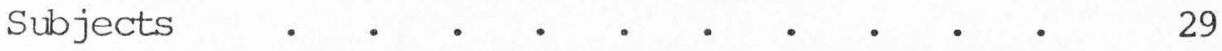

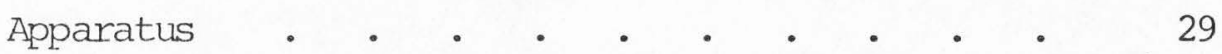

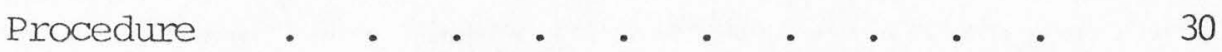

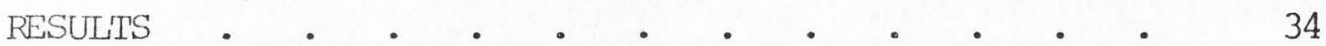

General Response Characteristics . . . . 34

Detailed Analysis of Choice Accuracy Patterns . 37

Comparison of FI and FR Performances . . . 42 
TABLE OF CONTENTSS (Continued)

Page

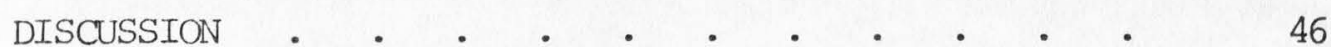

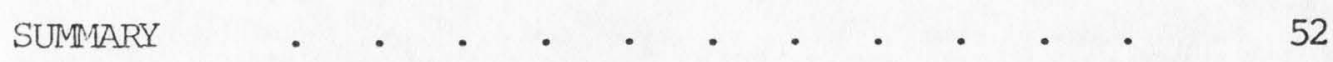

REFERENCES • • • • • • • • • • • • 53

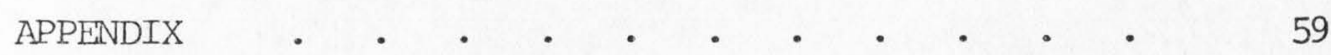

VITA $. \quad . \quad . \quad . \quad . \quad . \quad . \quad . \quad 61$ 


\section{LIST OF TABLES}

Table

Page

1. Order of Training on Reinforcement Schedules and the Number of Sessions Per Schedule

2. Per Cent Correct Trials for Each Bird Across the Last 10 Sessions of All Schedules

3. The Median Number of Correct Trials and the Median Interreinforcement Intervals Across the Last 10 Sessions on FR and FI Schedules for Each Subject. The Numbers in Parentheses are the Quarters of Trials or Intervals on Which Figures 2, 3, and 4 are Based. Time Measurements are in Multiples of 6 seconds

4. Randomized Sequence of FR 10 and FR 20 Trials Used Throughout the Experiment 
1. Selected cumulative response records of FR 10 and FR 20 performance for birds $\mathrm{Cl}$ and $\mathrm{C} 2$ from the last session on each schedule. Correct choice responses are indicated by a diagonal slash of the response pen. When a correct choice response was reinforced, the pen remained down during the reinforcement time. Errors are indicated by a dot above and to the left of a pause in responding. The recorder operated continuously during sessions . . . . . . 36

2. Choice accuracy across successive quarters of FI schedules for individual subjects. Data points to the right of the fourth quarter (hold or $h$ ) represent accuracy on trials that terminated after the timing out of the FI. The left ordinate is for FR 10 and FR 20 trials combined. The right ordinate is for FR 10 and FR 20 trials separately. The data are for the last 10 sessions of each schedule . . . . . 38

3. Choice accuracy across successive quarters of FR schedules for individual subjects. The right ordinate is for FR 10 and FR 20 trials separately. The left ordinate is for FR 10 and FR 20 trials combined. The data are for the last 10 sessions of each schedule.

4. Top panels: Choice accuracy across successive quarters of median correct interreinforcement trials on FI schedules for individual subjects. Data points to the right of the fourth quarter represent accuracy on trials that exceeded the fourth quarter. The number of correct trials in each quarter are shown in Table 3. Bottom panels: Choice accuracy across successive quarters of median interreinforcement intervals. Data points to the right of the fourth quarter represent accuracy on trials that exceeded the fourth quarter. The time intervals of each quarter are shown in Table 3. The data are from the last 10 sessions of each schedule . . . . . . . . 41 


\section{Effects of intermittent reinforcement upon fixed-ratio discrimination}

by

Tore Lydersen, Doctor of Philosophy

Utah State University, 1982

Major Professor: Carl D. Cheney

Department: Psychology

Four pigeons had discrimination training that required the choice of a left side-key following completion of a fixed-ratio 10 on the center key, and a right side-key response after fixed-ratio 20. Correct choices were reinforced on various fixed-interval, fixed-ratio, random-interval, and random-ratio schedules. When accuracy was examined across quarters of intervals (fixed-interval schedules) or quarters of median interreinforcement intervals (fixed-ratio schedules), accuracy was usually lower in the second quarter than in the first, third, or fourth quarters. When accuracy was examined across quarters of ratios (fixed-ratio schedules) or quarters of median number of correct interreinforcement trials (fixed-interval schedules), accuracy increased across quarters. These accuracy pattems did not occur on random-interval or random-ratio schedules. The results indicate that, when choice patterns differed on fixedinterval and fixed-ratio schedules, these differences were due to the methods of data analyses. 


\section{INTRODUCTION}

Background of Problem and Definition of Terms

A common technique used to establish a discrimination between two stimuli has been to reinforce responses directed to one stimulus and to not reinforce responses directed to the second stimulus. When the two stimuli are presented sequentially, a discrimination is said to exist when the stimulus associated with reinforcement controls a higher rate of responding than does the stimulus associated with nonreinforcement. When the two stimuli are presented simultaneously, choice rather than response rate is the most common discrimination index. Thus, a discrimination has been acquired when the stimulus associated with reinforcement is chosen more often than the stimulus associated with nonreinforcement. These examples may be considered as simple discriminations in that a constant relationship exists between stimuli and the consequences of behavior.

Of present interest are more complex procedures called conditional discriminations (Lashley, 1938). In these procedures the stimulus associated with reinforcement is not invariant, as in simple discrimination tasks, but instead, is dependent upon the stimulus context in which it appears.

Cumming and Berryman (1965) have described three different conditional discrimination procedures. The first is called matchingto-sample. Consider an example in which pigeons are presented 
with three adjacent, colored response keys. The center color is called the sample stimulus and the two side colors, one of which is identical to the sample, are called comparison stimuli. In this procedure, reinforcement is contingent upon choosing the comparison that matches the sample color. The color of the sample changes randomly following choice responses, thereby requiring the birds to choose different comparison colors across trials. Thus, samples serve an informative or instructional function (Cumming and Berryman, 1965).

A second type of conditional discrimination task is called oddity matching. Again, consider the example with three colored response keys. With oddity matching, reinforcement depends upon the choice of a comparison that differs from the sample, with the incorrect comparison being the same color as the sample.

The final class of conditional discrimination is called symbolic matching. Symbolic matching covers all procedures that are not matching-to-sample or oddity matching. An example would be a situation where two different tones serve as sample stimuli, with reinforcement contingent upon choosing one comparison color when one of the tones is presented, and choosing the second comparison color when the second tone is presented. Thus, the relationship between sample stimuli and correct comparisons is symbolic rather than dependent upon physical similarities or differences between sample and comparison stimuli. 
Research with conditional discrimination tasks has shown performance to be affected by a number of variables. These include: (1) the level of deprivation (Cumming, Berryman and Nevin, 1965; (2) extinction (e.g., Cumming, Berryman, Cohen and Johnson, 1967; Lydersen and Cheney, 1973); (3) the imposition of delays between presentation of samples and comparison stimuli (e.g., Berryman, Cumming and Nevin, 1963; Blough, 1959; D'Amato and O'Neill, 1971; Perkins, Lydersen and Beaman, 1973; Sidman, 1969); and (4) the number of stimuli presented as samples and comparisons (Cohen, 1969; Etkin and D'Amato, 1969).

In the cited studies, every correct choice response produced reinforcement. In operant terminology, this is a continuous reinforcement $(\mathrm{CRF})$ schedule. Another area of interest with conditional discrimination tasks has been to study the effects on choice of intermittent schedules of reinforcement. As the term intermittent implies, not all correct choices produce reinforcement on such schedules. For example, if a specific number of correct choices is required to produce reinforcement, the task is on a fixed-ratio (FR) schedule. Altematively, if the first correct choice response that occurs following the end of a specified interval of time produces reinforcement, the performance is an a fixed-interval (FI) schedule.

Performances produced by FR and FI schedules of reinforcement have been compared with each other as well as with schedules that result in reinforcement after an unpredictable number of correct 
choices (variable-ratio or VR schedule), or where reinforcement is presented for the first correct choice that occurs after the end of an unpredictable interval of time lapses (variable-interval or VI schedule).

Purpose of the Study

The present experiment studied the effects of various FI, FR, VI, and VR schedules of reinforcement on conditional discrimination performance. The task involved a discrimination between FR 10 and FR 20 responding, or FR discrimination. Of special interest was a study of the accuracy separately on each of the trials used. This seemed to be important because prior research has averaged the accuracy on all trials, thereby potentially obscuring significant relationships between certain trial types and choice accuracy pattems. $\underline{\text { Research Design }}$

The present research used a single-subject design. This procedure involved exposing each subject to several experimental treatments in a predetermined sequence. The performance of each subject's performance on the several experimental conditions were compared. Each of the four subjects were exposed to a different sequence of experimental conditions, thereby permitting a determination if any systematic effects occurred as a function of the particular order of exposure to the conditians. The overall accuracy of performances on FR 10 and FR 20 trials was determined. Additionally, the choice responses were recorded 
so that their temporal and ordinal locations within each interreinforcement interval could be determined. Iimitations and/or Delimitations of the Study

The present experiment studied the effects of intermittent reinforcement on FR discrimination performance in the pigeon. The accuracy pattems obtained were consistent with prior research that had used other tasks or other species of subjects, thereby extending the generality of the effects to the presently studied task. The finding that accuracy pattems were due largely to performances on only one type of trial could be specific to the task and procedures presently used; further research would be necessary to extend the generality of the present results to other tasks or species. 
REVIEW OF THE LITERATURE

The following review will examine, in detail, the effects of intermittent reinforcement upon conditional discrimination performance. To briefly preview, various schedules of reinforcement of conditional discrimination performance have been found to produce schedule-specific pattems of choice accuracy. These choice pattems will be described in considerable detail. In addition, the possible reasons why the choice pattems occur represent the main focus of the review. Finally, because intermittent reinforcement of simultaneous discrimination has produced effects that are similar to that obtained with conditional discriminations, this literature will also be considered.

\section{Conditional Discrimination}

Fixed-interval and variable-interval schedules. Ferster (1960) examined the effects of several schedules of reinforcement on matching-to-sample performance with two pigeons. Matching trials began with the presentation of either a red or a white sample stimulus on the center of three response keys. A response to the sample key tumed off the sample stimulus and, at the same time, transilluminated the two side keys, one with red and the other with white light. A response to the side, or comparison, key that matched the color of the sample produced 
reinforcement and then the next trial. Nonmatching comparison choices produced only a repetition of the same trial.

Ferster then studied a variety of schedules of reinforcement, of which FI and VI will be examined here. On FI schedules, the first correct choice response to be emitted after the end of the specified interval of time produced reinforcement. The FIs were examined alone (simple FI), or as one component of multiple FR FI schedules. On miltiple schedules, a pilot lamp of one color was on when the FR was in effect, and a different colored lamp was on when the FI was in effect.

The most notable result of FI reinforcement of matching-tosample was that regular changes in accuracy occurred across interreinforcement intervals. These changes in accuracy were demonstrated by determining accuracy within successive quarters of intervals. During the first quarter, the accuracy was moderately high. Choice accuracy then declined in the second quarter of intervals, followed by an increase within the third and fourth quarters. Because performance on various VI schedules did not produce these U-shaped accuracy pattems, this effect was due to some property of the FI schedule other than reinforcement frequency. However, the overall level of accuracy was about the same on both VI and FI schedules.

The U-shaped accuracy pattems that Ferster (1960) obtained on FI reinforcement of matching-to-sample have been replicated both with different procedures and with human subjects. Clark 
and Sherman (1970) trained pigeons on a two-key matching-tosample procedure similar to one devised by Cohen (1969). Trials started with both keys dark. A response to the dark left key produced a red or a green sample stimulus. Next, a response to the dark right key produced either a red or a green comparison stimulus. Additional responses to the right key produced a randomly ordered sequence of red and green comparisons. The color of the comparison was therefore controlled by the subject's behavior. A response to the left key when the left and right key colors matched produced reinforcement, while a response to the left key when the two colors were different produced only the next trial.

Following training with $\mathrm{CRF}$, the reinforcement schedule was gradually changed to FI $8 \mathrm{~min}$. Clark and Sherman also examined the effects of various stimuli that were occasionally paired with correct choices, incorrect choices, or reinforcement. However, only the baseline conditions without these stimuli is of present interest.

The results were consistent with those obtained by Ferster (1960). That is, across a combined total of 29 separate exposures to the FI 8 min baseline procedure by three pigeons, 12 resulted in the U-shaped interreinforcement accuracy pattern, with the lowest accuracy occurring in the second quarter. On the other baseline training conditions, the accuracy usually was lower in the first half of intervals than in the last half, but without 
the U-shaped patterns. An examination of the rate of trials completion indicated that the rate increased across the interreinforcement intervals. This is similar to the response rates typically abtained on FI reinforcement of free-operant responding (e.g., Ferster and Skinner, 1957).

In another study, Boren and Gollub (1972) trained pigeons on FI reinforcement of matching-to-sample. They used a three key procedure very similar to that used by Ferster (1960). The schedules studied were FI $t$, clock FI $t$, and chain FR 3 (FI $t$ ), with the values of t being $48 \mathrm{sec}, 96 \mathrm{sec}$, or $192 \mathrm{sec}$. On FI schedules, the first correct choice occurring after the end of the interval was reinforced. On clock FI, three different clock stimuli (blue, orange, and white pilot lights) were correlated with different thirds of intervals. The clock stimuli changed automatically at the end of each third. Finally, an chain FR 3 (FI), a correct choice response was required at the end of each FI component to change the color of the pilot light and to continue the interval. Reinforcement was presented for the first correct choice emitted at the end of three FIs.

Across all schedules, choice responses, measured in twelfths of intervals, were most accurate at the beginning and at the end of FIs; the lowest accuracy occurred between the second and seventh-twelfth of FIs. In addition, Bored and Gollub found a systematic relationship between accuracy and the rate at which trials were completed. At both high and low rates the accuracy 
was higher than at intermediate rates. The authors suggested that perhaps rate rather than accuracy was the most appropriate measure of schedule effects on conditional discrimination performances.

In a final study to be considered, Davidson and Osbome (1974) trained children on a matching-to-sample task similar to that described by Ferster (1960). In addition to the design changes necessary to adapt the procedure to children, the stimuli were horizontal and vertical lines rather than colors. The subjects were trained on simultaneous, zero-delay, and 2-sec delayed matching-to-sample reinforced on a variety of schedules, of which FI and VI will be considered here. On these schedules, every correct choice response produced a 1 sec flash from a lamp to the right of the three response keys, while errors produced only the next trial. The FI schedules tested ranged from 12 to $40 \mathrm{sec}$ and the VI schedules were either $24 \mathrm{sec}$ or $40 \mathrm{sec}$.

On FI schedules with simultaneous or $2 \mathrm{sec}$ delay procedures, subjects either did not attain stable performanoes, or they did not exhibit any consistent choice pattems. However, on zerodelay matching, all subjects had the lowest accuracy in the second quarter, or had equally low accuracy in the first and second quarters. In general, the effects of FI reinforcement on matchingto-sample appears to be more irregular with humans that with pigeons.

Other experiments have been conducted with II (Dews, 1963; 
Stubbs and Galloway, 1970) and VI (Ferster and Appel, 1961; Zimmerman and Bayden, 1963; Zinmerman and Ferster, 1963) reinforcement of conditional discrimination performance. However, they do not contain information that is pertinent to the present review.

Fixed-ratio and variable-ratio schedules. In the previously discussed study by Ferster (1960), he also examined matching-tosample performance maintained by FR schedules. When every correct choice response produced reinforcement (CRF or FR 1), matching was at about chance (50\%) accuracy. As the FR schedules were increased in size to FR 15 or FR 20, matching accuracy also increased. The accuracy then remained relatively stable until FR 35 was reached. At ratios beyond FR 35, choice accuracy gradually declined with further increases in ratio size.

Ferster's (1960) results with FR reinforcement of matchingto-sample were subsequently contradicted by results from a study by Nevin, Cunming and Berryman (1963). They used a threekey matching-to-sample task with three stimuli. Trials began with the presentation of red, blue, or green light on the sample key. The fifth response to the sample key produced two lit comparison keys, one of which matched the color of the sample while the other was one of the remaining two colors. A correct choice response produced reinforcement, followed by a 1 sec intertrial interval, while errors produced only the intertrial interval. The next trial was independent of the choice on the 
preceding trial.

During FR 1, a 96\% to $98 \%$ level of matching accuracy was obtained. With FR 3, the accuracy decreased to about $80 \%$, and then increased slightly with FR 6 and FR 10 schedules. When VR 3 was in effect, the choice accuracy was at about the same level as that obtained on FR 1. During matching on FR schedules, the choice accuracy was lowest at the start of ratios and then increased as the subject progressed through the ratio. This pattem was absent during VR 3, thereby indicating that the negatively accelerating accuracy pattem was produced by the predictable availability of reinforcement. Cumulative response records indicated that a period of no responding (i.e., postreinforcement pause) followed reinforcement on FR schedules, but not on VR reinforcement. These post-reinforcement pauses developed at the time that accuracy at the beginning of FRs began to decrease. The time required to complete trials at the beginning of FRs was also longer than that required later in the ratio. The results of Nevin et al. (1963), therefore, stand in sharp contrast to those of Ferster (1960). Notably, Ferster found chance accuracy with CRF (or FR 1) schedules, while Nevin et al. found near $100 \%$ accuracy on the same schedule. Nevin et al. noted that a number of procedural differences existed that might be responsible for the differing results:

(1) Nevin et al. used three stimuli while Ferster used two;

(2) Nevin et al. used simultaneous matching-to-sample while 
Ferster used zero-delay matching; (3) Nevin et al. used an intertrial interval while Ferster did not; (4) Ferster used a correction procedure while Nevin et al. did not; and (5) Ferster presented a brief hopper flash after correct but nonreinforced responses while Nevin et al. did not. Nevin et al. suggested that the correction procedure cound be responsible for a variety of response pattems not related to the sample stimuli and was, most likely, the variable responsible for the differing results.

Recent data suggest, however, that as far as the CRF discrepancies are concerned, the intertrial interval may be the crucial variable. Holt and Shafer (1973) examined both matching-to-sample acquisition and maintained matching under various intertrial interval durations. Trials began with the presentation of red, blue, or amber light on the sample key. The fifth response to the sample key produced the two comparison stimuli. Correct choice responses produced $3 \mathrm{sec}$ access to food, while errors produced a 2 sec blackout; errors also produced a repetition of the same trial.

For different birds, trials were separated by intertrial intervals of $0,5,15,25$, or 60 sec. The results were that most birds on $0 \mathrm{sec}$ intertrial intervals did not perform at much higher than chance (50\%) accuracy across 45 acquisition sessions. This is notable because, in a related matching-to-sample study, Cumming and Berryman (1961) dotained almost 100\% accuracy within 
10 sessions with a 25 sec intertrial interval.

Holt and Shafer also found that with a $5 \mathrm{sec}$ intertrial interval, one bird acquired matching at about $85 \%$ correct and a second bird performed at about chance. Two birds with $15 \mathrm{sec}$ intertrial intervals performed at $70 \%$ to $90 \%$ accuracy after 45 sessions. At $25 \mathrm{sec}$ and $60 \mathrm{sec}$ intertrial intervals, acquisition was rapid and produced nearly 100\% accuracy.

When birds that were initially trained with 0 sec intertrial intervals were subsequently placed on longer intertrial intervals, rapid acquisition occurred. However, when birds that had acquired with long intertrial intervals were placed on $0 \mathrm{sec}$ intertrial intervals, the matching performance typically decreased in accuracy. These results indicate, therefore, that long intertrial intervals facilitate matching-to-sample in some, as yet, unclear way.

Regardless of the final solution to the contradictory findings by Ferster (1960) and Nevin et al. (1963) regarding the effects of FR schedules on overall accuracy, the FR choice pattem has been demonstrated by other investigators. Mintz, Mourer and Weinberg (1966) trained pigeons on zero-delay matching-to-sample with reinforcement on an FR 9 schedule. In addition, there was a correlated counter associated with the FR 9 schedule. The correlated counter consisted of 10 white lamps mounted in a vertical row to the right of the response keys. At the start of ratios, the bottom lamp was lit. For 
each correct choice response the next lamp in the row was lit. On the ninth correct choice response, the tenth lamp came on and remained on during reinforcement. Thus, the correlated counter provided the birds with information as to exactly how many correct choices had been emitted within each FR. The results were that the number of errors was highest at the start of the FR count. Matching accuracy then increased as the subject advanced through the FR.

Next, a series of probes were run. On probe trials, the eighth lamp, rather than the first lamp, was lit following reinforcement. Thus, an FR 2 was in effect during probes. As before, each correct match lit the next lamp in the row. Although probes did not exactly replicate the last two steps of the FR 9 schedule performance, the accuracy was clearly higher than during the first two counts on FR 9. Thus, the correlated counter stimuli clearly exerted some degree of control over choice responding.

In a subsequent study that used the same procedure as Mintz et al. (1966), Mintz, Mourer and Stein (1968) examined the relationship between errors and the latency between each sample key response and choice responses. When errors occurred immediately after reinforcement, they were associated with relatively long choice latencies. As the FR count advanced, the errors became correlated with shorter latencies than were found with correct choices. Next, the birds were administered 
various dosages of librium and $\underline{d}$-amphetamine. It was found that drug levels that increased the latency between sample and choice responses also increased the accuracy of matching on trials toward the end of FRs. Conversely, drug-produced decreases in choice latency produced an increase in the occurrence of errors late in the ratio. Thus, both very long and very short latencies were correlated with errors.

In the previously described matching-to-sample study with children by Davidson and Osbome (1974), they also examined various FR and VR schedules of reinforcement. On FR, the choice accuracy was typically lowest in the first ordinal position of ratios. In subsequent ordinal positions the accuracy increased regularly for some subjects or changed unsystematically for others. In general, the clearest instances of negatively accelerating accuracy functions were found with zero-delay and 2 sec delayed matching. Simultaneous matching may have produced too high of an accuracy level, thereby resulting in a ceiling effect that could have prevented the development of systematic accuracy pattems. The primary effect of VR reinforcement was to lower the choice accuracy slightly from that abtained on FR. Further, no systematic choice pattems occurred with the VR schedules of reinforcement.

The effects of FR and VR reinforcement have also been studied with conditional discriminations other than matching-to-sample. For example, Stubbs (1968) required pigeons to discriminate 
between two temporal stimuli. In this experiment, trials started when the center of three response keys was transilluminated by orange light. A response changed the center key color to white. The white key then remained on for from 1 to $10 \mathrm{sec}$. At the end of the scheduled center key duration, the center key was tumed off and, at the same time, the two side keys were tumed on with red on one side and green on the other. A choice response to one side key color was correct if the center key had been on for a short duration ( 1 to $5 \mathrm{sec}$ ), while a choice response to the other side key color was correct if the duration had been long (6 to $10 \mathrm{sec}$ ). Correct choices produced either a $0.5 \mathrm{sec}$ illumination of the hopper light, or produced primary reinforcement, while errors produced a timeout during which the experimental chamber was dark.

For some conditions, the reinforcement schedule was FR 6. This produced the lowest accuracy at the first ordinal position of the FR; accuracy then increased as the subject progressed through the FR. The overall accuracy on FR 6 was about $90 \%$. Subsequently, the birds were rum an a VR 10 schedule. This resulted in an increase in the choice accuracy to near $100 \%$ and produced no systematic choice patterns.

Other experiments with conditional discriminations have used FR reinforcement (Dews, 1963; Ferster and Hammer, 1966; Randolph, 1969; Rohles, 1961; Stubbs and Galloway, 1970; Stubbs and Thomas, 1966). However, they did not study choice pattems. 


\section{Simultaneous Discrimination}

Nevin (1967) trained pigeons on a simultaneous brightness discrimination. All trials began with the presentation of two white response keys that differed in brightness. A response to the brighter key produced food, followed by a 6 sec intertrial interval; a response to the dimmer key produced only the intertrial interval. Additionally, if no response was emitted within $2 \mathrm{sec}$ of the start of trials, the intertrial interval started automatically. Thus, both the accuracy of the discrimination and the probability of responding were dependent variables. After stable choice responding was obtained, which was between $75 \%$ and $90 \%$ accuracy, the birds were trained on a series of random-trial ( $\mathrm{RT}$ ) schedules. On $\mathrm{RT}$, reinforcement was made available on randomly assigned trials. If an incorrect choice response occurred on a trial in which reinforcement was set up, the reinforcement availability was cancelled.

Under these conditions, choice accuracy remained relatively stable across six schedule parameters ranging from RT 1 to RT 50, with perhaps a slight downward trend at the higher RT values. The probability of responding within the $2 \mathrm{sec}$ trial duration also decreased slightly, from near 1.00 at RT 1 , as the schedule decreased in reinforcement probability.

Next, 10 sessions of extinction were instituted. During extinction, the probability of a response decreased to near-zero, but the accuracy of the few choice responses that did occur 
remained at about the same level as that obtained on $\mathrm{RT}$ schedules. This experiment demonstrated, therefore, that reinforcement frequency had little effect on choice accuracy. Further, the probability of a response was strongly affected only when reinforcement was witheld completely.

Nevin (1967) then studied performance on schedules that made reinforcement available according to fixed, rather than random, trial sequences. During fixed-trial (FT) schedules, reinforcement was made available on every fifth (FT 5) or tenth (FT 10) trial. If an incorrect trial occurred when reinforcement was available, the scheculed number of trials had to be repeated before reinforcement was again made available. Thus, both correct choices as well as errors advanced the trial count, but reinforcement was presented for a correct choice on every fifth or tenth trial. Also, as with the RT procedures, trials teminated after 2. sec if no response was emitted. On a second procedure, called fixed-ratio (FR), reinforcement was presented on every fifth (F'R 5) correct trial (i.e., errors did not count toward the ratio).

It was found that, on both FT and FR schedules, choice accuracy was uniformly high across trials. However, the probability of a choice response was a function of the number of trials since the last reinforcement. The probability of a response on the first trial was lower than at any other time. As the subject advanced through successive trials, thereby approaching the next reinforcer, the response probability increased 
systematically toward 1.00. Thus, the main finding was that the accuracy of a choice response was largely independent of the probability that a response would occur.

The failure to obtain systematic changes in accuracy across trials on FT or FR schedules differs from analogous data with conditional discrimination performances. As described earlier, Nevin et al. (1963) found matching-to-sample accuracy to be lowest immediately after reinforcement on FR schedules. Choice accuracy then increased as the subject progressed through the FR. Nevin (1967) noted that one major difference between his procedure and Nevin et al. was that matching-to-sample required a choice response on every trial, whereas the simultaneous discrimination procedures did not. Accordingly, Nevin (1967) conducted a third study in which an FR 5 schedule was in effect, but on which trials did not terminate until a response had been made. Under these conditions, the choice accuracy was lowest on the first trial on the FR schedule, followed by an increase in accuracy as the subject progressed through the ratio.

As a group, Nevin's (1967) experiments indicate that, once stimulus control has been established, it is independent of the variables that control other performance characteristics. In the presently examined series of studies, response probability clearly did not covary with choice accuracy. However, this generalization holds only when stimulus control measures are not confounded by forced choice contingencies such as those in 
the third experiment. The following simultaneous discrimination research is consistent with this conclusion.

Zeiler (1968) studied the effect of FR schedules on a discrimination between three simultaneously presented colors. A response to any of the three colors advanced the ratio count, but reinforcement was always dependent upon a response to one specific color. Also, the location of the three colors was changed according to a randomized sequence following every reinforcement. Zeiler found no consistent relationship between FR size and choice accuracy: overall accuracy was always near $100 \%$. Of the few errors that did occur, $70 \%$ to $80 \%$ were during the first quarter of ratios. The second quarter had about 20\% of the total number of errors, while the remaining two quarters each contained about 5\% of the errors.

The response patterns were usually similar to those abtained on simple FR schedules: each reinforcement was followed by a pause, and then by a run of responses that continued until the next reinforcer was obtained. When the schedule exceeded FR 33, occasional pauses occurred after the FR run had started. When extinction of choice responding was instituted, the rate of responding decreased across sessions. However, the few responses that continued to be emitted during extinction were to the stimulus formerly associated with reinforcement. Errors typically were restricted to the beginning of sessions or they followed pauses in responding. Again, this study suggests that stimulus control 
and response rates are controlled by separate variables. The finding that errors often occur after the post-reinforcement pause or after within-ratio pauses suggests that perhaps some relationship exists between the variable that controls pausing and that which determines the degree of stimulus control.

Zeiler (1970) trained pigeons on a three color simultaneous discrimination task similar to that used by Zeiler (1968). In this study, responses to one color produced food on various fixed-interval (FI) schedules, while responses to the two remaining colors had no scheduled effects. The location of the color associated with reinforcement changed randomly after every reinforcement. It was found that, across a series of FI values $(2,4,8$, and $16 \mathrm{~min})$, overall asymptotic accuracy was above $90 \%$. It was also found that the response rate increased systematically within intervals, much as is typical with free-operant FI responding (e.g., Ferster and Skinner, 1957). However, choice accuracy was constant within quarters of intervals. Next, the procedure was changed so that the location of the three colors were changed after each quarter of the FI. Both response-contingent and response-independent stimulus changes were studied. Under response-independent stimulus change the total accuracy declined slightly below that obtained on any other condition. Both of the quarterly stimulus change conditions did produce a marked decrease in response rates, with a minimum of $21 \%$ decrease in all quarters. The results 
indicate that the high choice accuracy obtained on other schedules of reinforcement was also obtained on FI schedules. This high accuracy was obtained regardless of the response rate, thereby indicating further that the variables that control response rate are independent of the variables that control choice accuracy .

Although the absence of a relationship between response rate and stimulus control has been shown in a number of ways by the preceding simultaneous discrimination studies, there were few attempts to explicitly control the rate of responding. The only exceptions were the extinction conditions (Nevin, 1967; Zeiler, 1968) that eventually produced near-zero rates. In a more recent experiment, Zeiler (1972) compared stimulus control and response. rates by controlling rate through differential-reinforcement-oflow-rates (DRL) schedules. On DRL schedules, a response is reinforced if it follows the preceding response by a minimum interval of time; early responses reset the interval. This contingency, therefore, producęd a slow rate of responding. Zeiler's study again involved a discrimination between three colors. Responses to only one of the colors were reinforced according to DRL 5, 10, 20, or 30 schedules. As in Zeiler's other experiments, the location of the color associated with reinforcement changed following the delivery of every reinforcer.

In an initial procedure, where responses to the incorrect stimulus had no consequences, accuracy ranged from $42 \%$ to nearly 
100\%. No consistent relationship was found between DRL value, response rate, or discrimination accuracy. Next, responses to the colors associated with extinction also reset the DRL interval. On this procedure the pigeons allocated at least $96 \%$ of their responses to the correct stimulus. However, there again was no clear relationship between DRL value, response rate, and the accuracy of the discrimination. Another measure of DRL performance is the proportion of responses that are reinforced to the total number of responses, or DRL efficiency. The efficiency ranged from a maximum of just below 0.50 at DRL $5 \mathrm{sec}$ to less than 0.01 at DRL $30 \mathrm{sec}$. This is consistent with free-operant studies that have examined similar ranges of DRL values with pigeons (e.g., Staddon, 1965) .

In a final procedure, extinction was examined for 18 sessions. As would be expected, extinction produced a steady decrease in response rate, but with a minimal effect on the discrimination itself. In most extinction sessions, at least $80 \%$ of the responses that were emitted were to the formerly correct stimulus. Again, stimulus control had no clear relationship to response rate. The level of correct responding on DRL schedules remained at levels comparable to that obtained on FR and FI schedules even though the obtained response rates were much lower.

These results are not limited to infrahuman subjects. Osborme and Bums (1975) found similar schedule effects both with children and adults on FR reinforcement of simultaneous 
discrimination performance. In this study, three different colors were presented at the same time on a stimulus panel located in front of the subject. Choice responses were made by pulling on one of the levers mounted below each stimulus. Reinforcement was produced by responding on the correct lever once after responses to any of the levers (correct or not) had advanced the ratio count to the point at which a correct response could produce reinforcement. A full exposure to the experimental conditions involved responding on an ascending, then descending series of ratios ranging from FR 1 to FR 16. Because the subjects could terminate their participation in the experiment at any time, only a few completed the entire sequence.

For most subjects on most schedules, accuracy was lower in the first half of ratios than in the second half. A notable exception was that one subject (a child) produced most errors in the last half of FRs from FR 2 to FR 14 during the ascending series. During subsequent portions of the experiment, this subject's errors predominated in the first half of the ratios.

It was also found that there were two main types of errors made by the subjects. The first type consisted of responding to a location that was presently associated with an incorrect stimulus, but which, on the immediately preceding ratio, was the location of the correct stimulus. This was called a win-stay response strategy. A second type or error occurred to locations 
that were not the location of the correct stimulus on the inmediately preceding ratio. A predominance of the first type of error was associated with low accuracy in the first half, while a predominance of the second type of error was associated with lowered accuracy in the second half of ratios.

It was suggested that these results indicate that response strategies are involved in the production of the typical pattems produced by FR reinforcement of choice responding. It should be noted, however, that because the authors did not go beyond a correlational analysis of the role of strategies in the production of choice patterns, their conclusion must remain speculative. Further research is clearly needed on this subject.

A final point of interest was that post-reinforcement pauses did not occur. This result clearly contradicts Zeiler's suggestion that the control of errors and the control of pausing seems to be closely related. Because of the considerable number of differences between Zeiler's (1968, 1970, 1972) work and that of Osborne and Burns, it is not presently possible to determine why their results differ in this regard.

Summary

Given the interest shown in the choice accuracy pattems produced by intemittent reinforcement of conditional điscrimination tasks, it seems suprising how poorly the effect is understood. The existing research has clearly shown that: (1) FI schedules frequently control lower accuracy in the second 
quarter of intervals than in the first, third, or fourth quarters, (2) FR schecules produce a negatively accelerating increase in accuracy across the ratio count, and (3) VI and VR schedules produce constant accuracy between reinforcements.

Although the absence of any notable effects produced by VI and VR schedules does not create any special difficulties, the FI and FR schedule performances present several problems. First, it is important to note that it is not really known if FR and FI controlled accuracy patterns differ from each other. Although the available data certainly encourage such a conclusion, an adequate demonstration of schedule-specific choice pattems has not been made. Specifically, FI patterns were detemined across time, while FR pattems were determined across correct trials. Thus, because different types of data analyses have been involved, the resulting choice patterns on FI and FR reinforcement cannot be compared directly. An explicit comparison of FI and FR accuracy patterns would require that the same type of analysis be applied to performances on both schedules. Thus, one problem that remains is to detemine if FI and FR patterms, in fact, differ.

A second problem involves a determination of why any choice patterns at all occur on FI and F'R schedules. This question remains whether or not FI and FR reinforcement is found to control different pattems. About all that the existing data clearly indicate is that only schedules that 
commonly produced pauses in responding following reinforcement are associated with the choice patterns presently under consideration. 
METHODS OF PROCEDURE

The present research attempted to determine if FI and FR choice accuracy pattems differ. This was accomplished by examining performances on the two types of schedules both across time and across correct trials, thereby permitting an explicit comparison of choice pattems. The conditional discrimination studied involved a discrimination between two different FR performances. Thus, the present study also was designed to extend the generality of schedule-controlled choice pattems to a discrimination between response-produced stimuli.

Subjects

Four male White King pigeons were used. The birds were reduced to about $75 \%$ of their free feeding weights by restricted feeding of Purina Racing Pigeon Checkers. All birds had about one year of prior training on conditional discriminations similar to that used in the present experiment (Lydersen and Cheney, 1973; Lydersen and Crossman, 1974).

Apparatus

Training was conducted in an experimental chamber containing three response keys and a food hopper. The interior of the chamber was $45.7 \mathrm{~cm}$ long, $61.0 \mathrm{~cm}$ wide, and $53.3 \mathrm{~cm}$ high. The response keys were $2.5 \mathrm{~cm}$ in diameter, $6.4 \mathrm{~cm}$ apart, center to 
center, $24.1 \mathrm{~cm}$ above the floor, and required a minimum force of about $0.15 \mathrm{~N}$ for operation. Reinforcement consisted of $5 \mathrm{sec}$ access to Purina Racing Pigeon Checkers through a $6.4 \mathrm{~cm}$ wide and $5.1 \mathrm{~cm}$ high aperture centered below the response keys. White light illuminated the aperture during reinforcement. A soundattenuating housing, white noise, and a ventilation fan served to mask extraneous stimuli. Chamber events were controlled by a system of electromechanical relays, timers, and stepping switches. Data were recorded by electromechanical counters and a cumulative recorder.

$\underline{\text { Procedure }}$

Because of prior experience with the task, the pigeons did not require any preliminary training. Each session consisted of a sequence of trials. Trials started with the transillumination of the center key with white light. Following the completion of either FR 10 or FR 20, the center key was darkened and the two side keys were transilluminated with green on the left and red on the right. On trials when FR 10 was in effect, a right side response produced reinforcement, while a left side response produced a 5 sec blackout during which the chamber was dark. On trials when FR 20 was in effect, a left side response produced reinforcement, while a right side response produced the $5 \mathrm{sec}$ blackout. The next trial followed immediately after reinforcement or blackout. The two FRs were scheduled equally often in a mixed, repeating block of 42 trials, restricted so that no more 
than three identical FRs could occur in succession. See Table 4, Appendix, for a list of the 42 trial block. Sessions terminated after 51 reinforcements. This continuous reinforcement (CRF) procedure continued until stable choice accuracy was obtained. Correct choices were then reinforced according to the schedules listed in Table $1 ;$ also shown is the order of training and the number of sessions on each schedule.

Fixed-ratio schedules specified the number of correct trials that were required to produce reinforcement. Nonreinforced correct and incorrect choices on FR, and all other schedules, produced a $5 \mathrm{sec}$ blackout and then the next trial. On randomratio (RR) schedules, reinforcement for correct choices was scheduled randomly, with the RR value specifying the mean number of correct choices required. On FI schedules, the first correct choice that occurred after the specified interval of time had lapsed produced reinforcement. Finally, on random-interval (RI) schedules, reinforcement for a correct choice was made available randomly in time, with the RI value specifying the mean time between reinforcement availability.

The first correct choice at the start of sessions always produced reinforcement. Subsequent reinforcements were abtained according to the prevailing schedule. Sessions were terminated after 31 reinforcements (FR 16, RR 16, FI $4 \mathrm{~min}$, and RI $4 \mathrm{~min}$ schedules), 51 reinforcements (all other schedules), or $4 \mathrm{hr}$, whichever occurred first. With few exceptions, sessions were 
Table 1. Order of Training on the Reinforcement Schedules and the Number of Sessions Per Schedule.

\begin{tabular}{|c|c|c|c|c|c|c|c|}
\hline \multicolumn{2}{|c|}{ Bird $\mathrm{Cl}$} & \multicolumn{2}{|c|}{ Bird C2 } & \multicolumn{2}{|c|}{ Bird C3 } & \multicolumn{2}{|c|}{ Bird C4 } \\
\hline Schedule & Sessions & Schedule & Sessions & Schedule & Sessions & Schedule & Sessions \\
\hline $\mathrm{CRF}$ & 38 & $\mathrm{CRF}$ & 44 & $\mathrm{CRF}$ & 31 & $\mathrm{CRF}$ & 41 \\
\hline FR 4 & 36 & FI 1 & 35 & RI 1 & 22 & $\mathrm{RR} 4$ & 22 \\
\hline FR 8 & 29 & FI 2 & 35 & RI 2 & 16 & RR 8 & 21 \\
\hline F'R 16 & 28 & FI 4 & 45 & RI 4 & 12 & RR 16 & 15 \\
\hline RR 4 & 16 & RI 1 & 26 & FI 1 & 44 & FR 4 & 36 \\
\hline RR 8 & 14 & RI 2 & 16 & FI 2 & 28 & FR 8 & 50 \\
\hline $\mathrm{RR} 16$ & 12 & RI 4 & 11 & FI 4 & 38 & FR 16 & 39 \\
\hline FI 1 & 33 & FR 4 & 30 & RR 4 & 18 & RI 1 & 18 \\
\hline FI 2 & 34 & FR 8 & 20 & RR 8 & 12 & RI 2 & 17 \\
\hline FI 4 & 47 & F'R 16 & 25 & RR 16 & 11 & RI 4 & 12 \\
\hline FI 2 & 37 & & & & & & \\
\hline
\end{tabular}


conducted daily.

Each schedule remained in effect until stable choice accuracy was obtained. Stability was assumed when the mean choice accuracy on each of two consecutive blocks of 5 sessions was within $2 \%$ of the combined 10 session mean. In addition, on FI and F'R schedules, the stability criterion was not applied until visual inspection of daily choice pattems revealed no systematic changes. 
RESULTS

The results indicate that choice pattems produced by intermittent reinforcement of FR discrimination are the same as those obtained with other tasks, but that FR and FI produced choice pattems do not differ from each other when identical data analyses are used. General Response Characteristics

The mean per cent correct choices across the last 10 sessions on each schedule for all birds is shown in Table 2 . Two general effects on accuracy controlled by the schedules of reinforcement can be seen. First, both FI and FR reinforcement produced lower choice accuracy than that obtained on CRF, RI, or RR. Second, both RI and RR reinforcement produced accuracy at, or slightly higher than, that controlled by CRF.

The effects of different values of any one type of schedule is less clear. Accuracy on FR reinforcement decreased as the ratio was increased in size for two birds ( $\mathrm{Cl}$ and $\mathrm{C} 4$ ), while the third bird (C2) had the lowest accuracy on FR 4. The effect of increasing the FI schedule was in the opposite direction: The choice accuracy of birds $\mathrm{Cl}$ and $\mathrm{C} 3$ increased with increases in FI time, while bird $\mathrm{C} 2$ had the highest accuracy on FI $1 \mathrm{~min}$.

Figure 1 shows selected portions of cumulative response records for birds $\mathrm{Cl}$ and $\mathrm{C} 2$. The $\mathrm{FI}$ and $\mathrm{FR}$ records are quite 
Table 2. Per Cent Correct Trials for Each Bird Across the Last 10 Sessions of All Schedules.

Subjects

\begin{tabular}{|c|c|c|c|c|}
\hline Schedule & $\mathrm{Bird} \mathrm{Cl}$ & ind C2 & Bird C3 & Bird C4 \\
\hline CRF & $93 \%$ & $92 \%$ & $91 \%$ & $92 \%$ \\
\hline F'R 4 & $82 \%$ & $81 \%$ & & $85 \%$ \\
\hline FR 8 & $82 \%$ & $86 \%$ & & $81 \%$ \\
\hline FR 16 & $80 \%$ & $84 \%$ & & $76 \%$ \\
\hline $\mathrm{RR} 4$ & $92 \%$ & & $94 \%$ & $89 \%$ \\
\hline RR 8 & $94 \%$ & & $95 \%$ & $88 \%$ \\
\hline RR 16 & $95 \%$ & & $96 \%$ & $91 \%$ \\
\hline FI 1 & $85 ㅇ$ & $87 \%$ & $81 \%$ & \\
\hline FI 2 & $86 \%(83 \%)^{a}$ & $84 \%$ & $84 \%$ & \\
\hline FI 4 & $88 \%$ & $84 \%$ & $90 \%$ & \\
\hline RI 1 & & $91 \%$ & $92 \%$ & $91 \%$ \\
\hline RI 2 & & $94 \%$ & $94 \%$ & $93 \%$ \\
\hline $\mathrm{RI} 4$ & & $93 \%$ & $95 \%$ & $92 \%$ \\
\hline
\end{tabular}

$a_{\text {Replication }}$ 


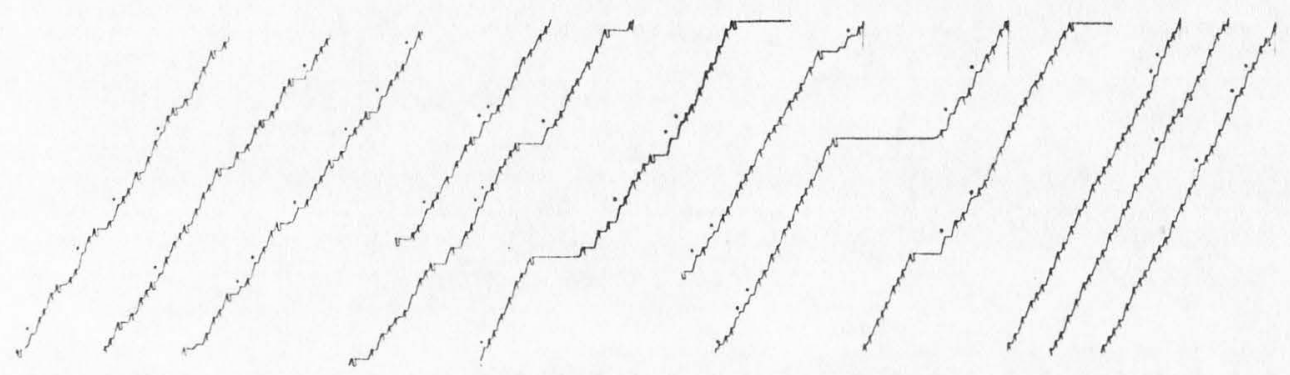

CIFR4 CIFR8 CIFR16 CIRR16
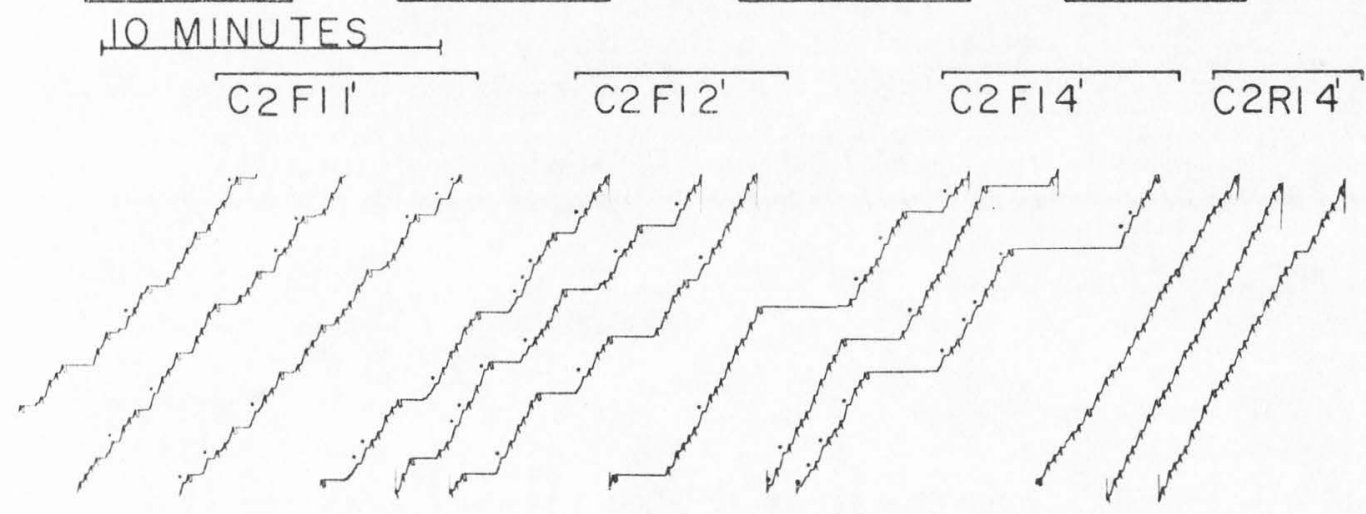

Figure 1. Selected cumulative response records of FR 10 and FR 20 performance for birds $\mathrm{Cl}$ and $\mathrm{C} 2$ from the last session on each schedule. Correct choice responses are indicated by a diagonal slash of the response pen. When a correct choice response was reinforced, the pen remained down during the reinforcement time. Errors are indicated by a dot above and to the left of a pause in responding. The recorder operated continuously during sessions. 
similar and will be discussed together. As shown, reinforcement was followed by a pause in responding. The first several trials after the pause typically resulted in correct choices if the stimulus ratio was FR 10. However, if the stimulus ratio was FR 20, the first several trials frequently resulted in errors. Responding on the first trials also was associated with occasional within-ratio pausing that rarely occurred in later trials. Beyond the first several trials, errors were infrequent, but with most errors still occurring on FR 20 trials.

On RI and RR schedules, trials were completed with few pauses. Of the pauses that did occur, most did not follow reinforcement and also did not differentially follow either FR 10 or FR 20 trials. With few exceptions, the cumulative response records of RI and RR performances were extremely similar across all schedule parameters. The occasional exceptions were individual sessions during which the rate of completion of RI trials slowed considerably. Similar effects were never abserved on RR reinforcement. Detailed Analyses of Choice Accuracy Pattems

Figure 2 shows the choice accuracy within successive guarters of intervals and following the end (hold) of the FI. On most FI schedules, the accuracy on trials that terminated in the first quarter was higher than the accuracy of trials that terminated within the second quarter. The choice accuracy then increased within the third and fourth quarters. For each 


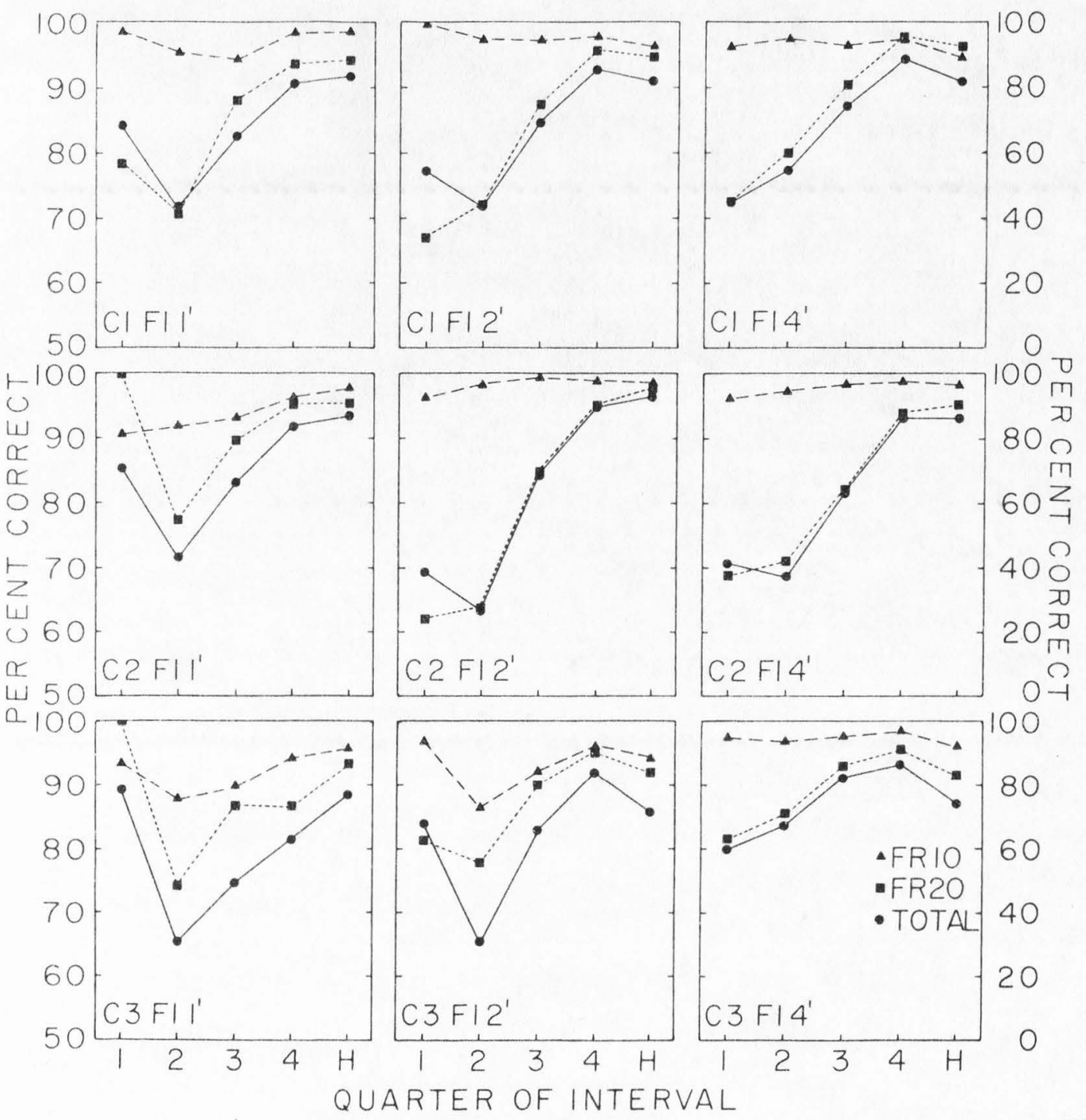

Figure 2. Choice accuracy across successive quarters of FI schedules for individual subjects. Data points to the right of the fourth quarter (hold or $h$ ) represent accuracy on trials terminated after the timing out of the FI. The left ordinate is for FR 10 and FR 20 trials combined. The right ordinate is for FR 10 and FR 20 trials separately. The data are for the last 10 sessions of each schedule. 
bird, the difference in accuracy between the first and second quarters decreased as the FI time was lengthened. At the longest schedule studied (FI $4 \mathrm{~min}$ ), only bird C2 had a higher choice accuracy in the first quarter. A second exposure to FI 2 min immediately after FI 4 min for bird Cl resulted in the first quarter accuracy again retuming to a higher level than that dotained in the second quarter. This suggests that the gradual change in accuracy pattems was not due solely to extended training an FI reinforcement.

Figure 2 also shows the choice accuracy across quarters separately on FR 10 and FR 20 trials. With few exceptions, the accuracy on F'R 10 trials was above $90 \%$ and was relatively stable across quarters. Of the errors that did occur, the majority were on FR 20 trials.

Figure 3 shows the per cent correct choices within successive quarters of ratios. On all FR schedules, the choice accuracy was lowest in the first quarter, followed by a systematic increase in accuracy across the second and third quarters. There was little difference between third and fourth quarter accuracy. This pattem was obtained with all birds, with no apparent differences occurring as a function of FR size. When the FR 10 and FR20 trials were examined separately (Figure 3), errors again typically predominated on FR 20 trials. The exception of bird $\mathrm{Cl}$ on FR 4 was produced by a reversal of errors on a few sessions and was not typical of performance on 


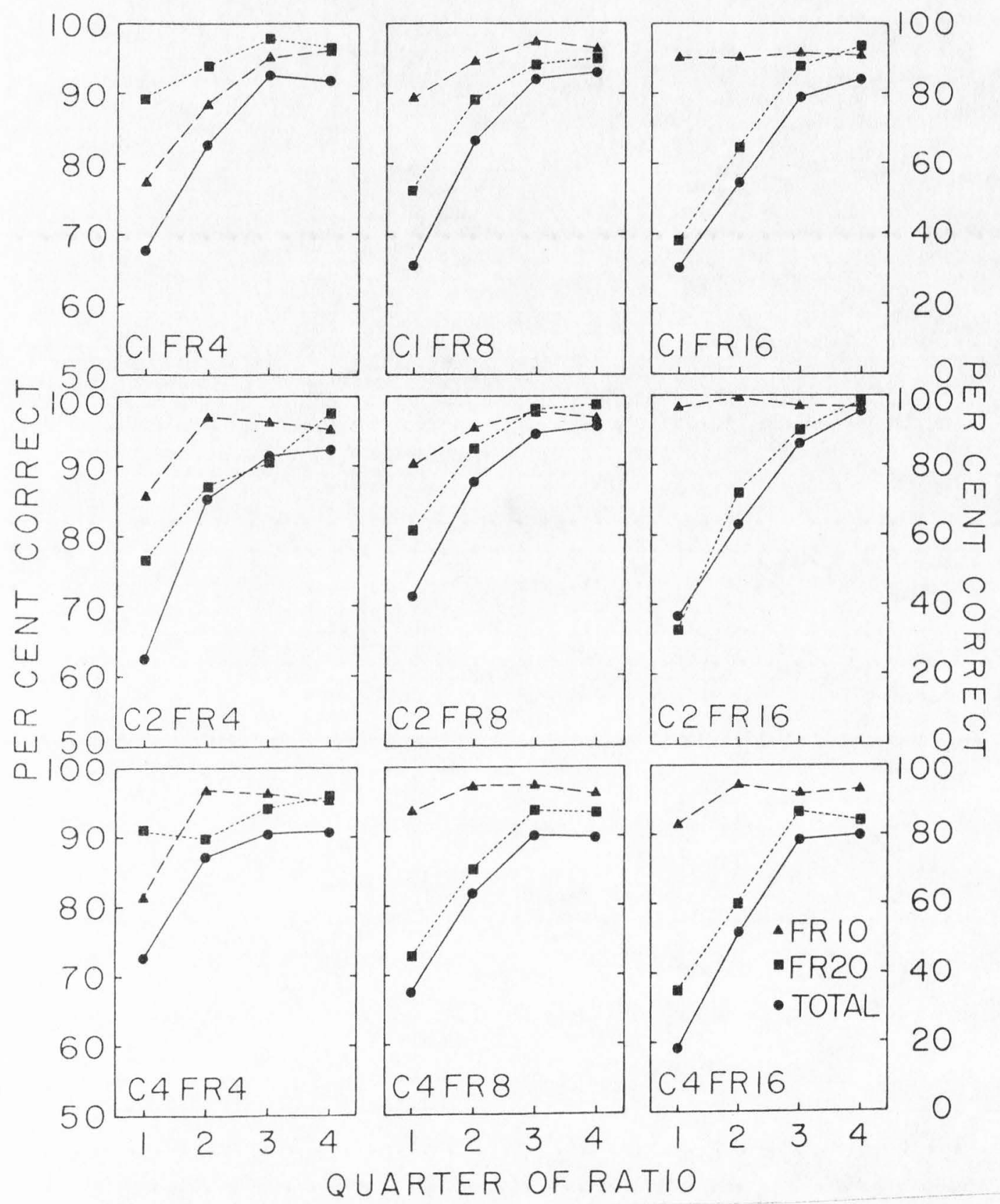

Figure 3. Choice accuracy across successive quarters of FR schedules for individual subjects. The right ordinate is for FR 10 and FR 20 trials separately. The left ordinate is for FR 10 and FR 20 trials combined. The data are for the last 10 sessions of each schedule. 


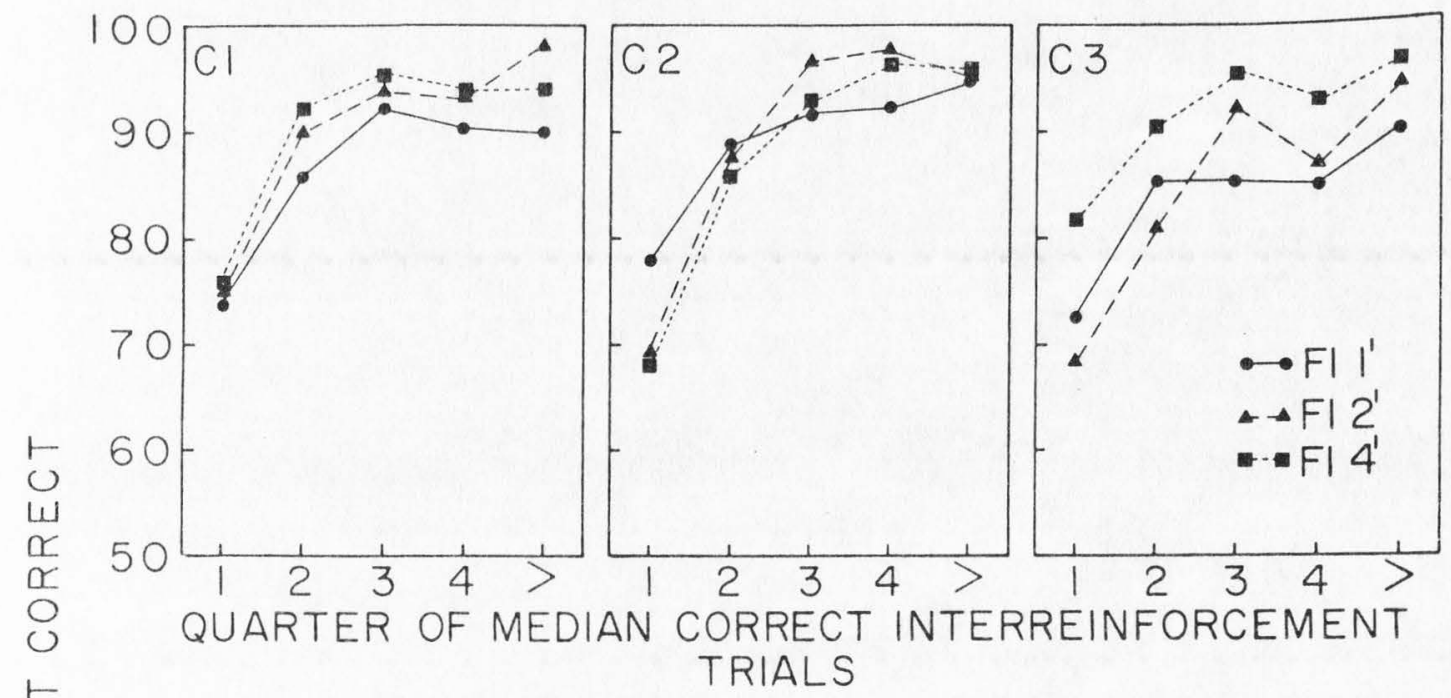

는

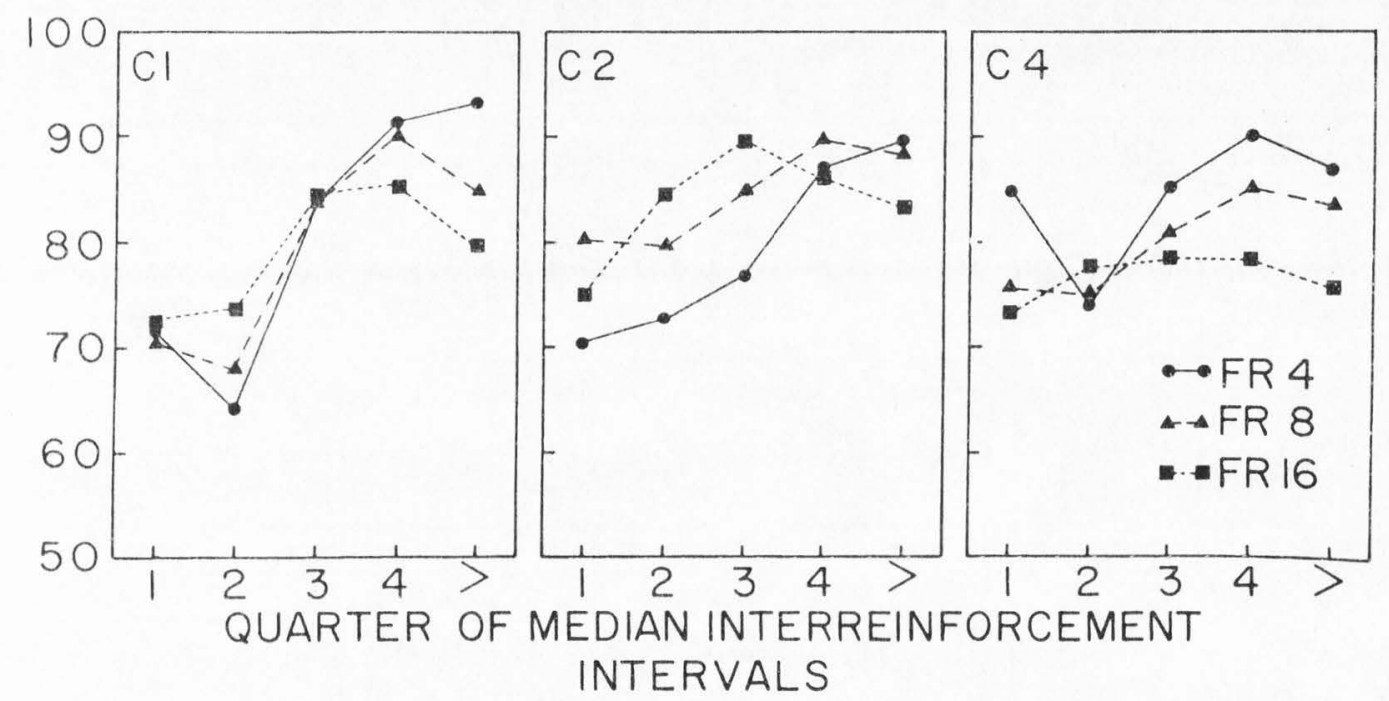

Figure 4. Top panels: Choice accuracy across successive quarters of median correct interreinforcement trials on FI schedules for individual subjects. Data points to the right of the fourth quarter represents accuracy on trials that exceeded the fourth quarter. The number of correct trials in each quarter are shown in Table 3. Bottom panels: Choice accuracy across successive quarters of median interreinforcement intervals on FR schedules. Data points to the right of the fourth quarter represent accuracy on trials that exceeded the fourth quarter. The time intervals of each quarter are shown in Table 3. The data are from the last 10 sessions of each schedule. 
the 10 sessions on which the Figure is based. Comparison of FI and FR Performances

In Figure 4, the choice accuracy patterns were redetermined to permit a comparison of FI and FR schedule performances. The top panels of Figure 4 show the FI performances determined across trials. The median number of correct trials across the last 10 sessions of each condition for all birds was computed separately. The obtained medians were then divided into quarters and the accuracy within each quarter was determined. The accuracy on trials that exceeded the fourth quarter are shown as the extreme right points on each curve. As shown, accuracy on FI schedules, when detemined across quarters of correct interreinforcement trials, increased across quarters. Thus, FI pattems determined across correct trials were similar to the FR patterns obtained across correct trials (Figure 2).

The bottom panels of Figure 4 show the FR performance determined across quarters of interreinforcement intervals. The median time between reinforcements across the last 10 sessions of each schedule for all birds was determined from measurement of cumulative response records in $6 \mathrm{sec}$ increments. The obtained medians were then divided into quarters and the accuracy within each quarter was computed. The points to the extreme right of each curve represent the accuracy on trials that exceeded the fourth quarter. As shown, five of the nine FR curves plotted according to quarters of median interreinforcement intervals 
had the lowest accuracy in the second quarter. Thus, FR patterns determined across time were similar to the patterns obtained on FI schedules also determined across time. The failure to find this effect on four FR schedules was due to the frequent occurrence of very long pauses following reinforcement. Because this resulted in very long quarters of interreinforcement intervals, the birds frequently completed the ratio requirement within one or two quarters. Thus, for these conditions, the resulting FR performances do not compare well with FI performances.

Table 3 presents the median number of correct trials and the median interreinforcement intervals on FI and FR schedules. As shown, the median number of correct choices on FI I min was identical or within one trial of that obtained on FR 4, and the time between reinforcements was also quite similar.

The number of trials in any quarter was a function of both the schedule of reinforcement and the method of data analysis. The total number of trials in each quarter of median correct interreinforcement trials decreased systematically across quarters of FI performance, but decreased only across the first three quarters on FR reinforcement: the third and fourth quarters contained approximately the same number of trials. The number of trials in each quarter of median interreinforcement intervals increased systematically across quarters on FI reinforcement. However, on FR reinforcement, the number of trials increased 
Table 3. The Median Number of Correct Trials and the Median Interreinforcement Intervals Across the Last 10 Sessions on FR and FI Schedules for Each Subject. The Numbers in Parentheses are the Quarters of Trials or Intervals on Which Figures 2, 3, and 4 are Based. Time Measurements are in Multiples of 6 Seconds.

Schedule Subject Median Number of Median Interreinforcement Correct Trials Intervals (sec)

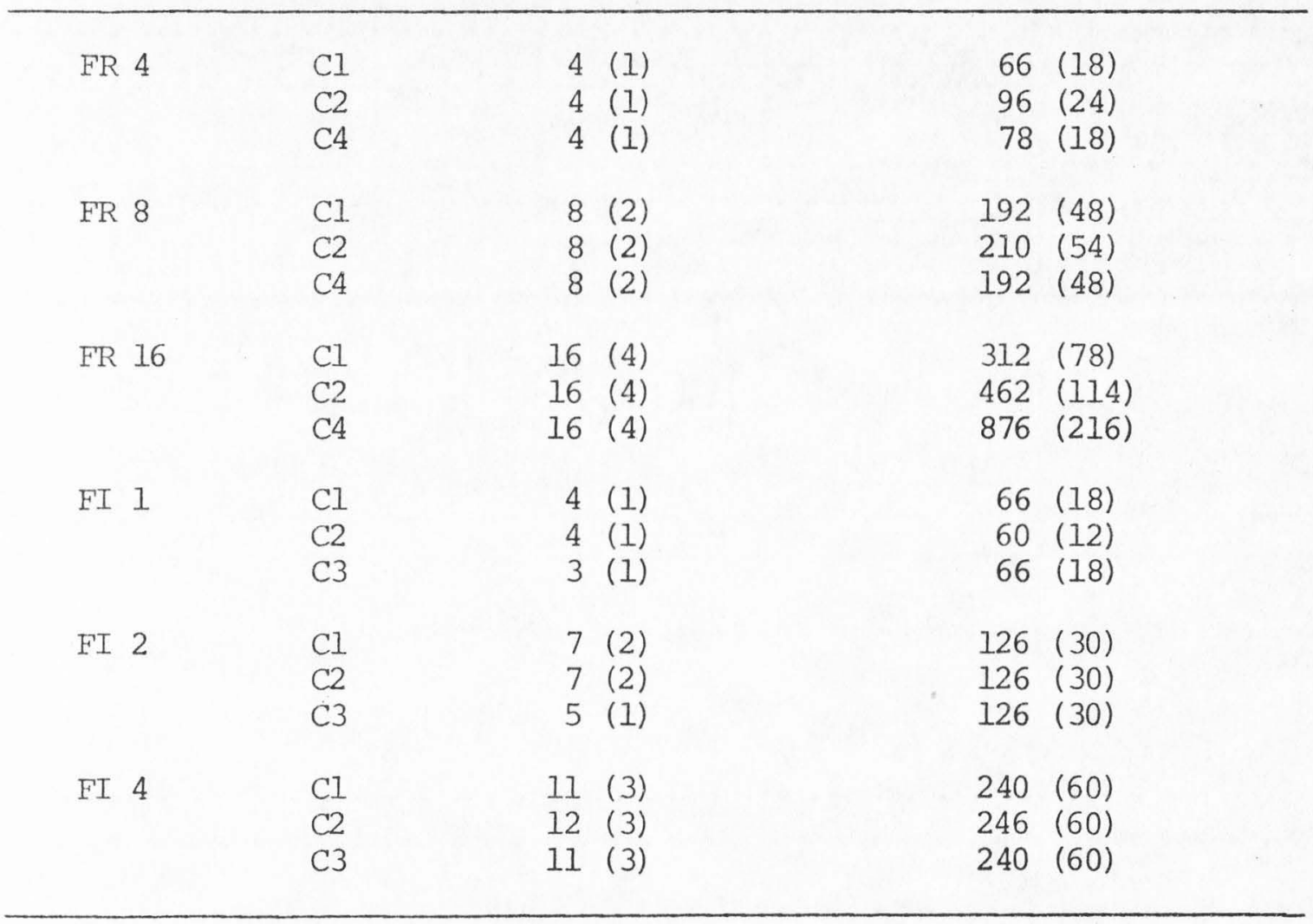


across the first three quarters and then decreased in the fourth quarter.

The accuracy in the first quarter of median interreinforcement intervals was correlated with the proportion of FR 10 trials contained within that quarter. For example, the highest accuracy in the first quarter (bird C3 on FI 1 min) was associated with $86 \%$ of all trials being FR 10 . When the accuracy was low or less than that obtained in the second quarter, a range of from 49\% (bird C4 on FR 16) to 57\% (bird $\mathrm{Cl}$ on $\mathrm{FI} 1 \mathrm{~min}$ ) of the trials were FR 10. Intermediate levels of choice accuracy were associated with intermediate percentages of FR 10 trials (e.g., 76\% for bird C2 on FI 1 min). 
DISCUSSION

The present study extends the known effects of intermittent reinforcement of conditional discrimination performance to an FR discrimination task. On FI reinforcement, choice accuracy was often lower in the second quarter of intervals than in the other three quarters. Further, FR reinforcement resulted in a systematic increase in accuracy as the ratio count advanced. Finally, on RI and RR schedules, choice accuracy was constant between reinforcements. Thus, the interreinforcement choice accuracy pattems were the same as those previously obtained with matching-to-sample and temporal discriminations (e.g., Ferster, 1960; Nevin et al., 1963; Stubbs, 1968).

Although the choice patterns differed on FI and FR reinforcement when performances were analyzed in the same way as has been done in prior studies, the results suggest that these differences were largely a function of the specific methods of data analyses. This was shown by an examination of performances both across time and across correct trials on FI and FR schedules. When the choice on FI schedules was determined across quarters of median correct interreinforcement trials, accuracy increased across successive quarters. These are the same accuracy pattems as those obtained on F'R schedules examined across quarters of correct interreinforcement trials. Similarly, when performance on FR schedules was determined across quarters of median 
interreinforcement intervals, the lowest accuracy frequently occurred in the second quarter, as did FI performances also determined across quarters of intervals. Thus, the present results indicate that FI and FR schedule-produced choice pattems were analysis-specific rather than schedule-specific.

As Boren and Gollub (1972) noted, comparisons of FI and FR performances are frequently made difficult because, in existing conditional discrimination studies, the two differed considerably on either the number of correct trials or on the time between reinforcements. The present procedures, however, permitted comparisons of performances on FI and FR schedules where both the interreinforcement intervals and the number of correct choices were nearly equal. Comparisons between FI I min and FR 4 schedules are especially appropriate because the number of correct trials were identical for all but one of the conditions (bird $\mathrm{C} 3$ on FI $1 \mathrm{~min}$ ), and the median interreinforcement intervals were also quite similar. The number of correct trials were also quite similar on FI 2 min and FR 8, as were the median interreinforcement intervals on FR 8 for bird C2 and FI 4 min for all birds. It seems reasonable to conclude that the accuracy patterns abtained on the presently examined schedules were not due to differences across schedules in either the number of correct choices or the median interreinforcement intervals.

A further result of the present study was that the FI and FR schedules affected accuracy primarily on only one of the two 
types of trials. For most conditions, errors predominated on F'R 20 trials, with these errors occurring primarily early during ratios and intervals. Thus, errors were associated both with the ratio that required the longest time to complete and with the choice preference of one of the two side keys. This selective effect suggests a partial explanation of the error patterns abtained across quarters of interreinforcement intervals. Because the post-reinforcement pause often exceeded the first quarter of interreinforcement intervals, relatively few trials terminated in the first quarter. However, of those that did terminate in the first quarter, a majority were FR 10 trials and were also correct. Thus, the per cent correct in the first quarter was biased because it contained a majority of trials that required the least time to complete and on which the preferred side key was correct. In the second quarter, the accuracy decreased because the first FR 20 trials in each interreinforcement interval typically terminated here and were frequently incorrect. The higher accuracy in the third and fourth quarters was due largely to the increasing accuracy on the FR 20 trials. When the temporal location of trials is not considered, the high, early accuracy does not occur because, in this case, accuracy is based on an approximately equal number of high accuracy FR 10 trials and low accuracy FR 20 trials. A difficulty with this analysis is that it should also 
account for accuracy pattems on other tasks such as matchingto-sample. That is, the time between the start of matching trials and a choice response should be consistently shorter in the presence of one of the sample stimuli than in the presence of other samples: This sample should also control higher accuracy than the other samples. Such differential times to complete trials has been shown during acquisition of matching-to-sample (Lydersen and Perkins, 1974), but apparently has not been examined during intermittent reinforcement of matching.

Another difficulty with the present analysis is that it does not explain why any pattems of choice accuracy occur at all on FI and FR schedules. It has been shown that errors tend to follow pauses in responding both on conditional discrimination performances (e.g., Ferster, 1960; Nevin et al., 1963) and on simultaneous discrimination performances (e.g., Nevin, 1967; Zeiler, 1968, 1970). Zeiler's (1968) suggestion that whatever controls pausing also controls errors is consistent with the present data. Precisely what controls both pauses and errors remains to be determined.

Boren and Gollub (1972) reported that intermediate rates of matching-to-sample were associated with more errors than were high or low rates on FI schedules. They suggested that peniaps rate was a "...more detailed and informative way..." (Boren, 1973) of analyzing matching than was choice accuracy. Davidson and 
Osbome (1974) made the related observation that the lowest accuracy was found when the greatest response rate change occurred. The present FI results agree with the findings of Boren and Gollub (1972) and Davidson and Osbome (1974), but not with their emphasis on response rate as an important dependent variable. That is, changes in rates were also closely associated with post-reinforcement pausing. Thus, first quarter rates were low not because of low rates per se, but rather because the post-reinforcement pause typically extended through the first quarter. Similarly, the increase in rate in subsequent quarters also was not due to increases in running rates, but rather occurred because less of the quarter time contained postreinforcement pausing. The high occurrence of errors in the middle of FIs was most likely due to the fact that errors tend to follow immediately after the post-reinforcement pause which, in tum, typically teminated during the middle of FIs (i.e., the portion of FIs associated with intermediate rates). Thus, the rate changes that occur during matching apparently are due largely to averaging and are probably not central to an understanding of the dotained choice pattems.

A final point to be considered is that the similarity in performances produced by FI and FR reinforcement suggests that the same variable controlled both performanoes. However, this experiment did not permit any conclusion regarding a specific source of control. Although there are some indi- 
cations that the number of responses contribute to schedule control (e.g., Crossman, Heaps, Numes and Alferink, 1974; Rilling, 1967), most research implicates time as the primary determinant (e.g., Killeen, 1969; Lydersen and Crossman, 1974; Neuringer and Schneider, 1968). In either case, it appears that schedule control is the same regardless of the complexity of the behavior being studied. 
SUMMARY

Four pigeons had FR discrimination performances reinforced according to various FI, FR, RI, and RR schedules. When accuracy was examined across quarters of interreinforcement intervals, accuracy on FI and FR reinforcement was commonly lower in the second quarter than in the first, or last two, quarters. When accuracy was examined across quarters of correct interreinforcement choices, accuracy increased across quarters. It was found that the errors were due largely to choices occurring on FR 20 stimulus trials. The accuracy pattems obtained on FI and FR reinforcement were absent during $\mathrm{RI}$ and $\mathrm{RR}$ reinforcement.

The main contribution of the present experiment was that the patterns of FI and FR choice accuracy were found to be, in part, a function of the methods of data analyses used. Further, the pattems obtained during FI and FR reinforcement were due largely to errors that occurred on one of the two types of trials that were involved in the discrimination. 
REFERENCES

Berryman, R., Cumming, W. W., and Nevin, J. A. Aoquisition of delayed matching in the pigeon. Journal of the Experimental Analysis of Behavior, 1963, 6, 101-107.

Blough, D. S. Delayed matching in the pigeon. Journal of the Experimental Analysis of Behavior, 1959, 2, 151-160.

Boren, M. C. P. Fixed-ratio and variable-ratio schedules of brief stimuli in second-order schedules of matching to sample. Joumal of the Experimental Analysis of Behavior, 1973, 20, 219-233.

Boren, M. C. P. and Gollub, L. R. Accuracy of perfonmance on a matching-to-sample procedure under interval schedules. Journal of the Experimental Analysis of Behavior, 1972, 18, $65-77$.

Clark, H. H. and Sherman, J. A. Effects of a conditioned reinforcer upon accuracy of match-to-sample. Journal of the Experimental Analysis of Behavior, 1970, 13, 373-384.

Cohen, L. R. Generalization during aoquisition, extinction, and transfer of matching with an adjustable comparison. Journal of the Experimental Analysis of Behavior, 1969, 12, 463-474. Crossman, E. K., Heaps, R. S., Nunes, D. L., and Alferink, L. A. The effects of number of responses on pause length with temporal variables controlled. Journal of the Experimental Analysis of Behavior, 1974, 22, 115-120. 
Cuming, W. W. and Berryman, R. Some data on matching behavior in the pigeon. Journal of the Experimental Analysis of Behavior, 1961, ㄴ, 281-284.

Cumming, W. W. and Berryman, R. The complex discriminated operant: studies of matching-to-sample and related problems. In D. I. Mostofsky (Ed.), Stimulus generalization. Stanford: Stanford University Press, 1965. Pp. 284-330.

Cumming, W. W. , Berryman, R. , Cohen, L. R., and Lanson, R. N. Some observations on extinction of a complex discriminated operant. Psychological Reports, 1967, 20, 1328-1330. Cumming, W. W., Berryman, R., and Nevin, J. A. Search for an effect of satiation on delayed matching-to-sample performance. Psychological Reports, 1965, 16, 645-652.

D'Amato, M. R. and O'Neil1, W. Effects of delay-interval illumination on matching behavior in the capuchin monkey. Journal of the Experimental Analysis of Behavior, 1971, 15, $327-335$.

Davidson, N. A. and Osbome, J. G. Fixed-ratio and fixed-interval schedule control of matching-to-sample errors by children. Joumal of the Experimental Analysis of Behavior, 1974, 21, $27-36$.

Dews, P. B. Behavioral effects of drugs. In S. M. Farber and R. H. L. Wilson (Eds.), Conflict and Creativity. New York: McGraw-Hil1, 1963. Pp. 138-153. 
Etkin, M. and D'Amato, M. R. Delayed matching-to-sample and short-term memory in the capuchin monkey. Joumal of Comparative and Physiological Psychology, 1969, 69, 544549.

Ferster, C. B. Intermittent reinforcement of matching to sample in the pigeon. Joumal of the Experimental Analysis of Behavior, 1960, 3, 259-272.

Frister, C. B. and Ippel, J. B. Pumishment of $S^{\Delta}$ responding in matching to sample by time out from positive reinforcement. Joumal of the Experimental Analysis of Behavior, 1961, $\underline{4}$, $45-56$.

Ferster, C. B. and Hammer, C. E., Jx. Synthesising the components of arithmetic behavior. In W. K. Honig (Ed.), Operant behavior: Areas of research and application. New York: Appleton-Century-Crofts, 1966. Pp. 634-676.

Ferster, C. B. and Skinner, B. F. Schedules of reinforcement. New York: Appleton-Century-Crofts, 1957.

llolt, G.I. and Schafer, J. N. Function of intertrial interval in matching-to-sample. Joumal of the Experimental Analysis of Behavior, $1973,19,181-186$.

Killecn, P. Reinforcement frequency and contingency as factors

in fixed-ratio behavior. Joumal of the Experimental Analysis of Bchavior, 1969, 12, 391-395.

Lashlcy, K. S. Conditional reactions in the rat. Joumal of Psychology, 1938, 6, 311-324. 
Etkin, M. and D'Amato, M. R. Delayed matching-to-sample and short-term memory in the capuchin monkey. Joumal of Comparative and Physiological Psychology, 1969, 69, 544549 .

Ferster, C. B. Intermittent reinforcement of matching to sample in the pigeon. Joumal of the Experimental Analysis of Behavior, 1960, 3, 259-272.

Ferster, C. B. and Appel, J. B. Punishment of $\mathrm{S}^{\Delta}$ responding in matching to sample by time out from positive reinforcement. Joumal of the Experimental Analysis of Behavior, 1961, $\underline{4}$, $45-56$.

Ferster, C. B. and Hanmer, C. E., Jr. Synthesising the components of arithmetic behavior. In W. K. Honig (Ed.), Operant behavior: Areas of research and application. New York: Appleton-Century-Crofts, 1966. Pp. 634-676.

Ferster, C. B. and Skinner, B. F. Schedules of reinforcement. New York: Appleton-Century-Crofts, 1957.

Holt, G.L. and Schafer, J. N. Function of intertrial interval in matching-to-sample. Joumal of the Experimental Analysis of Behavior, 1973, 19, 181-186.

Killeen, P. Reinforcement frequency and contingency as factors in fixed-ratio behavior. Joumal of the Experimental Analysis of Behavior, 1969, 12, 391-395.

Lashley, K. S. Conditional reactions in the rat. Joumal of Psychology, 1938, $\underline{6}, 311-324$. 
Nevin, J. A., Cumming, W. W., and Berryman, R. Ratio reinforcement of matching behavior. Journal of the Experimental Analysis of Behavior, 1963, 6, 149-154.

Osborne, J. G. and Bums, D. J. Error performance in a simultaneous discrimination employing fixed-ratio reinforcement. The Psychological Record, 1975, 25, 205-215. Perkins, D., Lydersen, T., and Beaman, D. Acquisition under mixed-delay and multiple-delay matching-to-sample. Psychological Reports, 1973, 32, 635-640.

Randolph, J. J. Some effects of fixed-ratio size and reinforcement frequency on the accuracy of a conditional discrimination performance. Psychonomic Science, 1969 , 14, 139-140.

Rilling, M. Number of responses as stimuli in fixed interval and fixed ratio schedules. Journal of Comparative and Physiological Psychology, 1967, 63, 60-65.

Rohles, F. H. The development of an instrumental skill sequence in the chimpanzee. Journal of the Experimental Analysis of Behavior, 1961, 4, 323-325.

Sidman, M. Generalization gradients and stimulus control in delayed matching-to-sample. Journal of the Experimental Analysis of Behavior, 1969, 12, 745-757.

Staddon, J. E. R. Some properties of spaced responding in pigeons. Joumal of the Experimental Analysis of Behavior, 1965, 8 , $19-27$. 
Stubbs, A. The discrimination of stimulus duration by pigeons. Joumal of the Experimental Analysis of Behavior, 1968, 11, 223-238.

Stubbs, A. and Galloway, W. D. Conditioned reinforcement and discrimination perfomance. Journal of the Experimental Analysis of Behavior, 1970, 14, 23-31.

Stubbs, A. and Thomas, J. R. Stimulus change effects on matching to sample performance. Psychonomic Science, 1966, 5, 115-116. Zeiler, M. D. Stimulus control with fixed-ratio reinforcement. Journal of the Experimental Analysis of Behavior, 1968, 11, $107-115$.

Zeiler, M. D. Fixed-interval stimulus control. Journal of the Experimental Analysis of Behavior, 1970, 14, 291-299.

Zeiler, M. D. Reinforcement of spaced responding in a simultaneous discrimination. Journal of the Experimental Analysis of Behavior, 1972, 18, 443-451.

Zimmerman, J. and Bayden, N. T. Punishment of $\mathrm{S}^{\Delta}$ responding of humans in conditional matching-to-sample by time-out. Journal of the Experimental Analysis of Behavior, 1963, 6 , $589-597$.

Zimmerman; J. and Ferster, C. B. Intermittent punishment of $\mathrm{s} \Delta$ responding in matching to sample. Journal of the Experimental Analysis of Behavior, 1963, $\underline{6}, 349-356$. 
APPENDIX 
Table 4. Randomized sequence of FR 10 and F'R 20 trials used throughout the experiment.

\begin{tabular}{|c|c|c|c|}
\hline Trial number & Trial FR & Trial number & Trial FR \\
\hline 1 & F'R 20 & 22 & FR 20 \\
\hline 2 & FR 20 & 23 & FR 20 \\
\hline 3 & FR 10 & 24 & FR 10 \\
\hline 4 & FR 10 & 25 & FR 20 \\
\hline 5 & FR 20 & 26 & FR 10 \\
\hline 6 & FR 20 & 27 & FR 10 \\
\hline 7 & FR 10 & 28 & FR 20 \\
\hline 8 & FR 20 & 29 & FR 20 \\
\hline 9 & F'R 20 & 30 & FR 20 \\
\hline 10 & FR 10 & 31. & FR 10 \\
\hline 11 & FR 20 & 32 & FR 20 \\
\hline 12 & FR 10 & 33 & FR 10 \\
\hline 13 & F'R 10 & 34 & F'R 20 \\
\hline 14 & FR 10 & 35 & FR 20 \\
\hline 15 & FR 20 & 36 & FR 10 \\
\hline 16 & F'R 10 & 37 & FR 20 \\
\hline 17 & FR 10 & 38 & FR 10 \\
\hline 18 & FR 20 & 39 & F'R 20 \\
\hline 19 & ER 10 & 40 & FR 10 \\
\hline 20 & FR 10 & 41 & FR 10 \\
\hline 21 & FR 20 & 42 & FR 10 \\
\hline
\end{tabular}




\author{
VITA \\ Tore Lydersen \\ Candidate for the Degree of \\ Doctor of Philosophy
}

Dissertation: Intermittent Reinforcement of Fixed-Ratio Discrimination

Major Field: Experimental Psychology

Biographical Information:

Personal Data: Born in Oslo, Norway, 5 December, 1942, son of Thorleif and Bodil Lydersen; married Barbara Ann Laslo, 28 January, 1963; three children - Julie Ann, Tore Stephen, and Dana Marie.

Education: Attended elementary school in Oslo, Norway and Bellingham, Washington; graduated from Ballard High School, Seattle, Washington, 1961; received the Bachelor of Arts degree with a major in psychology from California State University, Fullerton, 1969; received the Master of Arts degree in psychology from California State University, Fullerton, 1972.

Professional Experience: Employed by the California Department of Mental Health at Metropolitan State Hospital, Norwalk, California, 1964 to 1972; research assistant for Dr. E. K. Crossman, Utah State University, 1972 to 1973; teaching assistant, Department of Psychology, Utah State University, 1973 to 1974; manager of the Utah State University Psychology Animal Laboratory, 1974; Assistant Professor, Department of Psychology, Fort Hays Kansas State College, Hays, Kansas.

Publications and Paper Presentations:

Lydersen, T. and Perkins, D. Effects of duration of DRL correlated stimuli on timing and collateral responding. Psychonomic Science, 1972, 29, 149-151.

Beaman, D., Perkins, D., and Lydersen, T. Acquisition of mixed delay and multiple delay matching-to-sample. Presented at the Rocky Mountain Psychological Association, Albuquerque, 1972. 
Lydersen, T. and Perkins, D. Effects of responseproduced cues upon acquisition and transfer of zero delay conditional discrimination. Presented at the Rocky Mountain Psychological Association, Albuquerque, 1972 .

Lydersen, T. and Perkins, D. Matching accuracy as a function of simple, mixed, and multiple fixed-ratio observing response requirements. Presented at the Utah Academy of Sciences, Arts, and Letters, Salt Lake City, 1972.

Perkins, D. , Lydersen, T., and Beaman, D. Acquisition under mixed-delay and multiple-delay matching-tosample. Psychological Reports, 1973, 32, 635-640.

Lydersen, T., Perkins, D., and Chairez, H. Spatial vs non-spatial fixed-ratio discrimination. Presented at the Rocky Mountain Psychological Association, Las Vegas, 1973.

Chairez, H., Perkins, D., and Lydersen, T. Acquisition and maintenance of 0-delay oddity. Presented at the Rocky Mountain Psychological Association, Las Vegas, 1973.

Lydersen, T. and Cheney, C. D. The effects of extinction and satiation upon fixed-ratio discrimination. Presented at the Utah Academy of Sciences, Arts, and Letters, Ogden, 1973.

Lydersen, T. and Cheney, C. D. Fixed-ratio discrimination: effects of extinction and satiation. Journal of Biological Psychology, 1973, 15, 26-29.

Lydersen, T. and Crossman, E. K. Effects of responseproduced blackouts on fixed-ratio discrimination. Presented at the Utah Academy of Sciences, Arts, and Letters, Logan, 1974.

Gill, C. , Lydersen, T., and Perkins, D. Acquisition and transfer of 0-delay matching under compound and single stimulus conditions. Presented at the Rocky Mountain Psychological Association, Denver, 1974.

Lydersen, T. and Perkins, D. Effects of responseproduced stimuli upon conditional discrimination performance. Journal of the Experimental Analysis of Behavior, 1974, 21, 307-314. 
Lydersen, T. and Crossman, E. K. Fixed-ratio discrimination: effects of response-produced blackouts. Joumal of the Experimental Analysis of Behavior, 1974, 22, 547-551.

Lydersen, T. and Cheney, C. D. Effects of intermittent reinforcement upon fixed-ratio discrimination. Presented at the Psychonomic Society, Denver, 1975.

Perkins, D., Lydersen, T., and Chairez, H. Fixed-ratio discrimination: comparison of spatial and nonspatial choice procedures. Perceptual and Motor Skills, 1976, $43,587-593$.

Lydersen, T., Perkins, D., and Chairez, H. Effects of fixed-ratio sample and choice response requirements upon oddity matching. Joumal of the Experimental Analysis of Behavior, 1977, 27, 97-101. 